УДК 331.461

ЧАСТОТНЫЙ АНАЛИЗ ОТКАЗОВ ГАЗОПРОВОДОВ, РАБОТАЮЩИХ В УСЛОВИЯХ СЕВЕРА

\title{
FREQUENCY ANALYSIS OF FAILURES ON GAS PIPELINES OPERATING IN THE NORTH
}

\begin{abstract}
А.М. Большаков, М.И. Захарова
Институт физико-технических проблем Севера им. В.П. Ларионова СО РАН - структурное подразделение ФИЦ «Якутский научный центр СО РАН», г. Якутск, Российская Федерация
\end{abstract}

\author{
Aleksandr M. Bolshakov, Marina I. Zakharova
}

V.P. Larionov Institute of the Physical-Technical Problems of the North of the Siberian Branch of the RAS, Yakutsk, Russian Federation

$$
\text { e-mail: marine3@yandex.ru }
$$

Аннотация. Суровые природно-климатические условия Севера значительно снижают надежность и безопасность эксплуатации газопроводов. Неконтролируемое развитие аварийных ситуаций может привести к катастрофическим разрушениям и гибели людей.

Анализ риска представляет собой один из существенных компонентов обеспечения безопасности и проводится для выявления отдельных источников опасности и оценки их потенциального влияния на возможные ущербы, которые могут быть причинены населению, окружающей среде и хозяйственным объектам.

Важнейшим этапом анализа риска является оценка частоты или вероятности отказов и сценариев развития аварийных ситуаций на газопроводах. 
По результатам анализа отказов газопроводов, произошедших в условиях Севера, выявлены основные причины аварий газопроводов, разработано дерево отказов утечки газа из газопровода с оценкой частот реализации отказов.

Статистический анализ причин аварий газопроводов показал, что основными факторами возникновения этих событий являются организационные причины, связанные с человеческим фактором и технические причины, связанные со старением и износом газопроводов и коррозионными повреждениями.

Частота утечки газа из газопровода составила $1,3 \cdot 10^{-3} 1 /($ км·год), из них утечка газа при полном разрыве газопровода $-1,74 \cdot 10^{-4}$ 1/(км·год). Наиболее частыми отказами являются отказы из-за дефектов сварного шва $3,09 \cdot 10^{-4} 1 /(\kappa м \cdot г о д)$, механического воздействия третьих лиц $2,9 \cdot 10^{-4} 1 /($ км·год), сквозных коррозионных повреждений $2,51 \cdot 10^{-4} 1 /$ (км·год) и износа материала трубы $-1,74 \cdot 10^{-4} 1 /$ (км·год).

По результатам анализа известных аварий газопроводов, произошедших при низких температурах, разработано дерево событий истечения газа из газопровода с оценкой частот реализации аварийных сценариев. Выявлены наиболее опасные сценарии развития аварии на газопроводе, которые возникают с частотой порядка $10^{-5} 1 /$ (км ·гд).

При постоянном нахождении человека в зоне возможного действия поражающих факторов индивидуальный риск будет порядка $10^{-5} 1 /($ км ·год), что соответствует зоне жесткого контроля риска.

Таким образом, оценка риска аварий газопроводов, работающих в условиях Севера, на основе критериев приемлемого риска позволит оценить опасности с неприемлемым уровнем риска и послужит основой для разработки рекомендаций и мер по уменьшению опасностей.

Abstract. Severe natural and climatic conditions of the North significantly reduce reliability and safety of gas pipelines operation. Uncontrolled development of emergency situations can lead to catastrophic destruction and loss of life. 
Risk analysis is one of the essential components of safety and is carried out to identify individual sources of hazards and to assess their potential impact on possible damage that may be caused to the population, the environment and economic facilities. The most important stage of risk analysis is assessment of frequency or probability of failures and scenarios of emergency development in gas pipelines.

Based on the results of gas pipeline failures analysis occurred in the North, the main causes of gas pipeline accidents were identified, the gas leak «fault tree» from the gas pipeline was developed with estimation of failures frequencies

Statistical analysis of the causes of gas pipeline accidents showed that the main causes of these events are organizational causes related to the human factor and technical reasons related to aging and wear of gas pipelines and corrosion damage.

The frequency of gas leakage from the gas pipeline is $1,3 \cdot 10^{-3} 1 /(\mathrm{km} \cdot \mathrm{year})$, of which gas leakage at complete pipe rupture $-1,74 \cdot 10^{-4} 1 /(\mathrm{km} \cdot$ year). The most frequent failures are failures due to welding defects $3,09 \cdot 10^{-4} \quad 1 /(\mathrm{km} \cdot$ year$)$, mechanical effects of third parties $2,9 \cdot 10^{-4} 1 /(\mathrm{km} \cdot y e a r)$, corrosion damages $-2,51 \cdot 10^{-4} 1 /(\mathrm{km} \cdot \mathrm{year})$ and wear of material $-1,74 \cdot 10^{-4} 1 /(\mathrm{km} \cdot$ year $)$.

Based on the results of analysis of known accidents of gas pipelines, which occurred at low temperatures, «event trees» of gas leakage from the gas pipeline has been developed with estimation of emergency scenarios frequencies.

The most dangerous scenarios of accidents on the gas pipeline that occur with a frequency of about $10^{-5} 1 /(\mathrm{km} \cdot$ year) have been identified.

With the constant presence of a person in the zone of possible action of damaging factors, the individual risk will be about 10-5 1/(km ггод) that corresponds to strict risk control zone.

Thus, accidents risk assessment of gas pipelines operating in the North, based on acceptable risk criteria, will allow to assess hazards with an unacceptable level 
of risk and will serve as a basis for the development of recommendations and measures to reduce hazards.

Ключевые слова: частота отказов; частота аварийных ситуаций; оценка риска; нормирование риска; газопроводы Севера

Key words: failures frequencies; frequency of emergency situations; risk assessment; risk rationing; gas pipeline of the North

\section{Введение}

Газопровод является важным элементом системы газоснабжения, так как на его сооружение расходуется 70-80 \% всех капитальных вложений. При этом из общей протяженности газопроводов 70-80 \% составляют газопроводы низкого давления и только 20-30 \% - газопроводы среднего и высокого давления. Газопроводы низкого давления служат для подачи газа к жилым домам, общественным зданиям и коммунально-бытовым предприятиям. Газопроводы среднего давления через газорегуляторные пункты снабжают газом газопроводы низкого давления, a также промышленные и коммунально-бытовые предприятия. По газопроводам высокого давления газ поступает через газораспределительные установки на промышленные предприятия и газопроводы среднего давления.

Большая часть северных газопроводов имеет подземную конструктивную схему прокладки и расположена в зоне распространения многолетнемерзлых грунтов. Суровые природно-климатические условия Севера значительно снижают надежность и безопасность эксплуатации газопроводов. Неконтролируемое развитие аварийных ситуаций может привести к катастрофическим разрушениям и гибели людей.

Анализ риска представляет собой один из существенных компонентов обеспечения безопасности и проводится для выявления отдельных источников опасности и оценки их потенциального влияния на возможные 
ущербы, которые могут быть причинены населению, окружающей среде и хозяйственным объектам.

\section{Основные причины аварий газопроводов, эксплуатирующихся} в условиях Севера

Важнейшим этапом анализа риска является оценка частоты или вероятностей отказов и сценариев развития аварийных ситуаций на газопроводах.

По результатам анализа отказов газопроводов, произошедших в условиях Севера, выявлены основные причины аварий газопроводов (таблица 1).

Таблица 1. Основные причины аварий газопроводов в условиях Севера

\begin{tabular}{|l|l|c|}
\hline № & \multicolumn{1}{|c|}{ Наименование фактора } & $\begin{array}{c}\text { Доля } \\
\text { фактора }\end{array}$ \\
\hline 1 & Возможные механические воздействия третьих лиц & 0,22 \\
\hline 2 & Сквозные коррозионные повреждения & 0,20 \\
\hline 3 & Ошибки при сварочных работах & 0,24 \\
\hline 4 & Природные воздействия & 0,02 \\
\hline 5 & Накопление повреждений, износ материала & 0,13 \\
\hline 6 & Ледяные закупорки & 0,03 \\
\hline 7 & Разгерметизация фланца & 0,16 \\
\hline
\end{tabular}

Статистический анализ причин аварий газопроводов показал, что основными факторами возникновения этих событий являются организационные причины, связанные с человеческим фактором и технические причины, связанные со старением и износом газопроводов и коррозионными повреждениями.

Механические воздействия третьих лиц составляют 22 \% от возможных причин возникновения аварии. Основными факторами, способствующими механическому повреждению газопровода, являются нарушения охранных зон газопровода; высокая плотность населения на территориях, 
прилегающих к трассе газопровода и уровень производственнохозяйственной активности на территории газопровода.

По анализу статистических данных вероятность повреждения газопровода при наличии нарушений охранной зоны составляет 0,05, влияние человеческого фактора $-0,15$.

На вероятность случайного или намеренного нарушения целостности газопровода влияют такие аспекты эксплуатации, как существование между эксплуатирующей газопровод организацией и сторонними организациями строгой системы согласования проведения работ в охранной зоне, контроля их проведения; осведомленность населения и персонала предприятий и организаций, находящихся на территориях, прилегающих к трассе газопровода, о расположении его трассы, правилах поведения и проведения работ в охранной зоне газопровода, опасных последствиях при повреждениях газопровода.

Сквозные коррозионные повреждения составляют 20 \% от возможных причин возникновения аварии. Основная опасность коррозионного разрушения наружной поверхности газопроводов возникает при подземной прокладке. Коррозионные повреждения возникают под воздействием грунта или блуждающих токов в местах нарушения изоляции или дефектов изоляции газопроводов. По результатам анализа статистических данных, вероятность сквозной коррозии при повреждении изоляционного покрытия составляет 0,3. Своевременные обследования состояния изоляции и поверхности трубы значительно снижают вероятность образования сквозного коррозионного повреждения.

Одним из наиболее частых причин отказов является дефект сварного шва, который составляет 24 \% от возможных причин возникновения аварии. Все отклонения от технологических параметров, вызванные небрежностью в работе, нарушением режимов и внешними причинами, часто не зависящими от сварщика, могут привести к возникновению дефектов в сварочном шве и околошовной зоне, попадающей в область термического 
воздействия. К дефектам приводит и нарушение технологических приемов как самого процесса сварки, так и некачественная подготовка, неисправность оборудования, отклонения от норм качества сварочных материалов, влияние погодных условий, низкая квалификация сварщика.

Дефекты сварочных швов могут быть наружными и внутренними.

К наружным дефектам сварных швов относят нарушение размеров и формы шва, подрезы и другие отклонения, которые могут быть обнаружены при внешнем осмотре сварного соединения.

К внутренним дефектам сварных соединений относят поры, шлаковые включения, непровары, несплавления и трещины.

Внутренние трещины - самые опасные дефекты сварного соединения, часто приводящие к его разрушению. Проявляются они в виде разрыва в сварном шве или в прилегающих к нему зонах. Сначала трещины образуются с очень малым раскрытием, но под действием напряжений их распространение может быть соизмеримо со скоростью звука, в результате чего происходит разрушение конструкции.

Причинами образования трещин являются большие напряжения, возникающие при сварке. Чтобы свести к минимуму вероятность появления дефектов, следует учитывать:

- технологию сварки и квалификацию сварщика;

- присадочный материал и свариваемый металл;

- подготовку поверхности под сварку и защитный газ;

- режимы и применяемое сварочное оборудование.

Таким образом, работоспособность сварных конструкций (в частности, трубопроводов) во многом определяется качеством сварных швов, которое напрямую зависит от соблюдения технологии сварки, а также от квалификации сварщика и качества применяемых сварочных материалов. Износ материала трубы составляет 14 \% от возможных причин возникновения аварии. По результатам анализа статистических данных, вероятность разрыва газопровода, эксплуатирующегося более 30 лет, 
составляет 0,06. Многочисленные обследования показывают, что подземные газопроводы, работающие при нормальных режимах, находятся в удовлетворительном состоянии благодаря систематическому контролю состояния подземных газопроводов и своевременной ликвидации появляющихся дефектов. Но общее техническое состояние линейной части этих газопроводов с каждым годом ухудшается, так как эксплуатационный ресурс практически исчерпан. Моральный и физический износ линейной части газопроводов привел на сегодняшний день к непрерывному увеличению затрат на восстановление и объемов работ по ликвидации и частичному предупреждению аварий. В связи с этим проблема прогнозирования вероятности разрушений стареющих газопроводов становится актуальной и важной. При старении металла труб газопровода происходят необратимые изменения механических свойств и характеристик трещиностойкости [1], что приводит к повышению вероятности возникновения катастрофического разрушения с выбросом значительного количества взрывопожароопасного вещества.

Оценка частот реализации отказов и сценариев развития аварийных ситуаций на газопроводах Севера

По результатам анализа статистических данных разработано дерево отказов утечки газа из газопровода с оценкой частот реализации отказов (рисунок 1). 


Нарушение
охранной
зоны
$\mathrm{F}_{\mathbf{1}}=\mathbf{4 , 9 4 \cdot 1 0 ^ { - 3 }} 1 /$ (кмгод)

Повреждения изоляционного покрытия $\mathrm{F}_{2}=\mathbf{1 , 4 8 \cdot 1 0 ^ { - 3 }} 1 /$ (кмчод)

Ошибки при
сварочных
работах
$\mathrm{F}_{3}=\mathbf{3 , 0 9 \cdot 1 0 ^ { - 4 }} 1 /$ (кмгод)

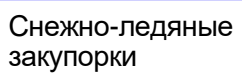

Неудовлетворительное состояние фланцев $\mathrm{F}_{7}=\mathbf{3 , 3 2 \cdot 1 0 ^ { - 4 }} 1 /$ (кмгод)

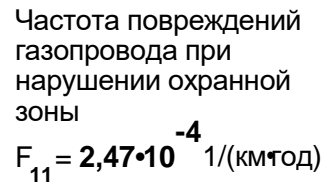

Частота повреждений газопровода при нарушении охранной зоны

$F_{11}=2,47 \cdot 10^{-4} 1 /($ кмчод)

Частота повреждений газопровода

от механического воздействия при проведении работ в охранной зоне $\mathrm{F}_{12}=4,35 \cdot 10^{-5} 1 /$ (кмгод)

Частота возникновения
сквозных коррозионных
повреждений
$F_{21}=\mathbf{2 , 5 1 \cdot 1 0}$

Частота утечки газа от сквозных коррозионных повреждений $F_{02}=2,51 \cdot 10^{-4} 1 /($ кмгод)

\section{Дефект сварного шва \\ $\mathrm{F}_{31}=3,09 \cdot 10^{-4} 1 /($ кмгод)}

Частота утечки газа по сварному

$\mathrm{F}_{03}=3,09 \cdot 10^{-4} 1 /$ (км॰од)

Частота повреждения газопровода при морозобойном растрескивании грунта $\mathrm{F}_{41}=1,93 \cdot 10^{-5} 1 /$ (кмгод)

Частота утечки газа при морозобойном растрескивании грунта $\mathrm{F}_{04}=1,93 \cdot 10^{-5} 1 /($ кмгод)

Частота разрыва газопровода из-за накопления

повреждений и износа материала трубы (возраст трубы свыше 30 лет)

$F_{51}=1,74 \cdot 10^{-4} 1 /($ кмгод)

Частота разрушения
газопровода при
ледяных закупорках
$\mathrm{F}_{61}=\mathbf{3 , 8 7 \cdot 1 0 ^ { - 5 }} 1 /$ (кмгод)
газа при ледяных закупорках

$F_{06}=3,87 \cdot 10^{-5} 1 /($ кмгод)

из-за накопления

повреждений

и износа трубы

$F_{05}=1,74 \cdot 10^{-4} 1 /($ кмгод)

Разгерметизация фланца

$F_{71}=2,13 \cdot 10^{-4} 1 /($ кмчод)
Частота утечки газа по фрланцевому соединению $F_{07}=2,13 \cdot 10^{-4} 1 /($ кмгод)

Рисунок 1. Дерево отказов утечки газа из газопровода в условиях Севера

Частота утечки газа из газопровода составила $1,3 \cdot 10^{-3}$ 1/(км·год) (рисунок 1), из них утечка газа при полном разрыве газопровода - 
$1,74 \cdot 10^{-4} 1 /($ км·год). Наиболее частыми отказами являются отказы из-за дефектов сварного шва $-3,09 \cdot 10^{-4} 1 /($ км·год), механического воздействия третьих лиц $-2,9 \cdot 10^{-4}$ 1/(км·год), сквозных коррозионных повреждений $2,51 \cdot 10^{-4} 1 /\left(\right.$ км·год) и износа материала трубы $-1,74 \cdot 10^{-4} 1 /($ км·год).

Сущность анализа риска заключается в отборе и обработке всей доступной информации для идентификации опасности и оценки ее возможных последствий.

Обобщение вероятностей аварий по различным сценариям удобнее всего осуществлять логико-вероятностными методами деревьев событий и деревьев отказов (ДО/ДС). Широкое использование методов ДО/ДС вызвано простотой и ясностью исходной идеи, используемой при постановке задачи моделирования.

Построение дерева событий позволяет проследить последствия каждого возможного исходного события и вычислить максимальную вероятность главного события от каждого из таких исходных событий. Но основная ценность метода дерева событий связана с возможностью на проектном уровне выявить различные последовательности событий, приводящих к главному событию, и тем самым определить возможные последствия каждого из исходных событий. Метод дерева событий прост по форме и легко интерпретируется. В общем случае как деревья отказов, так и деревья событий являются лишь наглядной иллюстрацией к простейшим вероятностным моделям. Однако они представляют значительный интерес для специалистов, связанных с эксплуатацией, обслуживанием и надзором технических объектов. Имея такую схему, специалист, даже не обладая основательными знаниями по теории вероятностей, может не только найти наиболее критический вариант развития событий, но и оценить ожидаемый риск, если соответствующее дерево событий или отказов дополнено статистическими данными.

По результатам анализа известных аварий газопроводов, произошедших при низких температурах, разработано дерево событий истечения газа из 
газопровода [2] с оценкой частот реализации аварийных сценариев (рисунок 2).

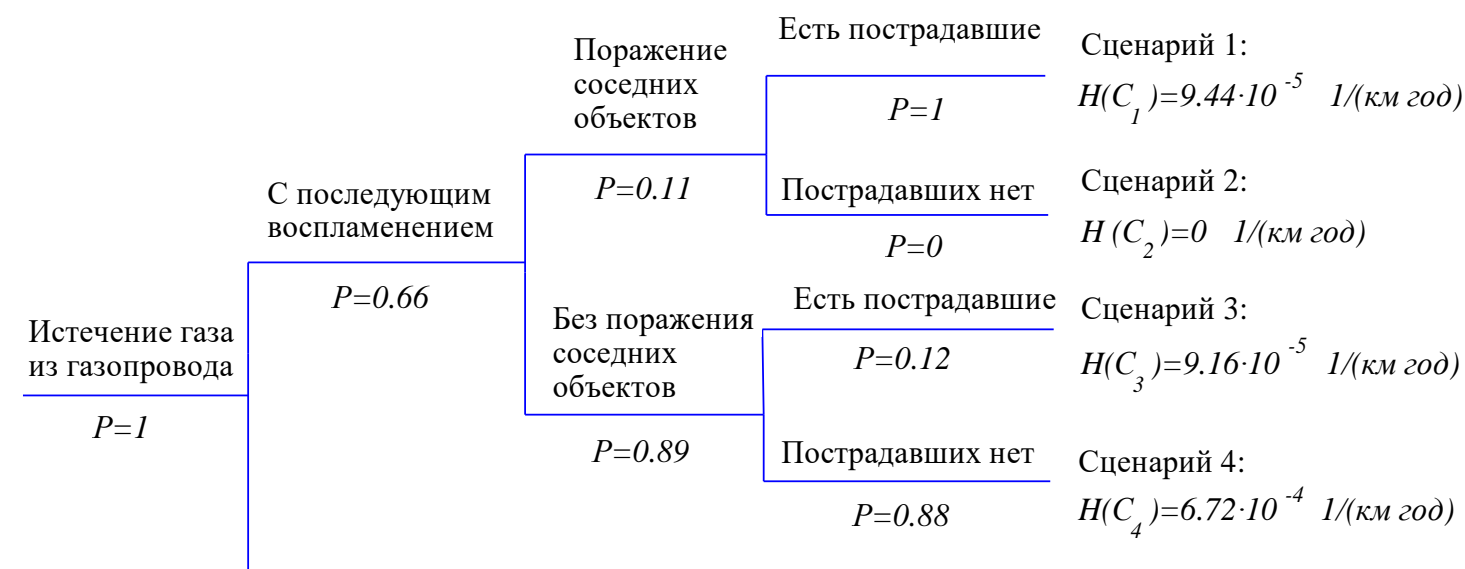

Образование взрывоопасного облака ГВС метана

Без последующего воспламенения

$$
\begin{array}{ll}
P_{1}=0.92 & \text { (ноябрь }) \\
P_{2}=0.98 & \text { (декабрь }) \\
P_{3}=0.94 & \text { (январь) } \\
P_{4}=0.83 & \text { (февраль) }
\end{array}
$$

Рассеивание газовой смеси без образования опасных концентраций

$$
\begin{array}{ll}
P_{1}=0.08 & \text { (ноябрь) } \\
P_{2}=0.02 & \text { (декабрь }) \\
P_{3}=0.06 & \text { (январь) } \\
P_{4}=0.17 \text { (февраль) }
\end{array}
$$

Сценарий 5:

при малых объемах утечки газа

$H_{1}\left(C_{5}\right)=4.07 \cdot 10^{-4} 1 /(\kappa м ~ г о д)$ (ноябрь)

$\mathrm{H}_{2}\left(\mathrm{C}_{5}\right)=4.33 \cdot 10^{-4} 1 /(\kappa \mathrm{колд)} \mathrm{(декабрь)}$

$\mathrm{H}_{3}\left(\mathrm{C}_{5}\right)=4.15 \cdot 10^{-4} 1 /(\kappa м г о д)$ (январь)

$H(C)=2.82 \cdot 10^{-4} 1 /($ км год) (февраль)

Сценарий 5:

при больших объемах утечки газа (разрыв газопровода)

$H_{1}\left(C_{5}\right)=5.44 \cdot 10^{-5} 1 /(\kappa м ~ г о д)$ (ноябрь)

$H_{2}\left(C_{5}\right)=5.8 \cdot 10^{-5} 1 /(\kappa м г о д)$ (декабрь)

$\mathrm{H}_{3}\left(\mathrm{C}_{5}\right)=5.56 \cdot 10^{-5} 1 /(\kappa м г о д)$ (январь)

$H_{4}\left(C_{5}\right)=4.91 \cdot 10^{-5} 1 /($ км год) (февраль)

Сценарий 6:

при малых объемах утечки газа

$H_{1}\left(C_{6}\right)=3,54 \cdot 10^{-5} 1 /(\kappa м ~ г о д)$ (ноябрь)

$H_{2}\left(C_{6}\right)=8,84 \cdot 10^{-6} 1 /(к м г о д)$ (декабрь)

$\mathrm{H}_{3}\left(\mathrm{C}_{6}\right)=2,65 \cdot 10^{-5} 1 /(\kappa м г о д) \quad$ (январь)

$H_{4}\left(C_{6}\right)=7,51 \cdot 10^{-5} 1 /(\kappa м г о д)$ (февраль)

Сценарий 6:

при больших объемах утечки газа (разрыв газопровода)

$H_{1}\left(C_{5}\right)=4.73 \cdot 10^{-6} 1 /(\kappa м ~ г о д)$ (ноябрь)

$H_{2}\left(C_{5}\right)=1.18 \cdot 10^{-6} 1 /(\kappa м г о д)$ (декабрь)

$\mathrm{H}_{3}\left(\mathrm{C}_{5}\right)=3.55 \cdot 10^{-6} 1 /(\kappa м г о д)$ (январь)

$H_{4}\left(C_{5}\right)=1.01 \cdot 10^{-5} 1 /($ км год) (февраль)

Рисунок 2. Дерево событий истечения газа из газопровода при низких температурах окружающей среды 
Частоты реализации сценариев определяем по следующей формуле [3]:

$$
H\left(C_{j}\right)=F \cdot \prod_{i} P_{j i},
$$

где $F$ - частота истечения газа из газопровода, $1 /($ км ·год);

$P_{j i}$ - вероятности событий сценария $(j, i=1,2,3, \ldots .$,$) ;$

$C_{j}$ - сценарии реализации аварийных ситуаций $(j=1,2,3, \ldots)$.

Нормирование риска наряду с идентификацией, оценкой и прогнозом является составной частью количественного анализа риска аварий. Одновременно нормирование выступает и как элемент процесса управления безопасностью в техносфере.

Одной из наиболее часто употребляемых характеристик опасности является индивидуальный риск - вероятность (или частота) поражения отдельного индивидуума в результате воздействия исследуемых факторов опасности при реализации неблагоприятного случайного события. Этот вид риска рассматривается в качестве первичного и основного понятия в связи с приоритетом человеческой жизни как высшей ценности и позволяет осуществлять установление приемлемого и неприемлемого уровней риска.

В работе [4] предложены следующие уровни критериев индивидуального риска для населения от действующих опасных производственных объектов: уровень риска более $10^{-4}$ в год - зона недопустимого риска; менее $10^{-4}$ в год, но более $10^{-5}$ в год - зона жесткого контроля риска; менее $10^{-5}$ в год - зона приемлемого риска.

По результатам анализа дерева событий истечения газа из газопровода (рисунок 2) наиболее опасные события возникают с частотой порядка $10^{-5} 1 /($ км год). При постоянном нахождении человека в зоне возможного действия поражающих факторов индивидуальный риск будет порядка $10^{-5} 1 /($ км ·год), что соответствует зоне жесткого контроля риска. 


\section{Выводы}

Оценка риска аварий газопроводов, работающих в условиях Севера, на основе критериев приемлемого риска позволит оценить опасности с неприемлемым уровнем риска и послужит основой для разработки рекомендаций и мер по уменьшению опасностей.

\section{Список используемых источников}

1. Махутов Н.А., Лебедев М.П., Большаков А.М., Захарова М.И. Особенности возникновения чрезвычайных ситуаций на газопроводах в условиях Севера // Вестник Российской академии наук. 2017. Т. 87. № 9. C. 858-862. DOI: 10.7868/S0869587317090158.

2. Захарова М.И. Оценка риска аварийного истечения газа из газопровода при аномальных метеоусловиях Севера // Проблемы анализа риска. 2018. Т. 15. № 2. С. 78-85.

3. Bolshakov A.M., Zakharova M.I. Operational Risks for Gas Pipelines at Low Temperatures // Russian Engineering Research. 2016. Vol. 36. No. 1. P. 3538. DOI: 10.3103/S1068798X16010081.

4. Елохин А.Н. Анализ и управление риском: теория и практика. М.: Полимедиа, 2002. 191 с.

\section{References}

1. Makhutov N.A., Lebedev M.P., Bol'shakov A.M., Zakharova M.I. Osobennosti vozniknoveniya chrezvychainykh situatsii na gazoprovodakh $\mathrm{v}$ usloviyakh Severa [Features of Emergency Situations on Gas Pipelines in the North]. Vestnik Rossiiskoi akademii nauk - Herald of the Russian Academy of Sciences, 2017, Vol. 87, No. 9, pp. 858-862. DOI: 10.7868/S0869587317090158. [in Russian]. 
2. Zakharova M.I. Otsenka riska avariinogo istecheniya gaza iz gazoprovoda pri anomal'nykh meteousloviyakh Severa [Risk Assessment of Emergency Gas Outflow from a Gas Pipeline under Abnormal Weather Conditions in the North]. Problemy analiza riska - Issues of Risk Analysis, 2018, Vol. 15, No. 2, pp. 78-85. [in Russian].

3. Bolshakov A.M., Zakharova M.I. Operational Risks for Gas Pipelines at Low Temperatures. Russian Engineering Research, 2016, Vol. 36, No. 1, pp. 35-38. DOI: 10.3103/S1068798X16010081.

4. Elokhin A.N. Analiz i upravlenie riskom: teoriya i praktika [Analysis and Risk Management: Theory and Practice]. Moscow, Polimedia Publ., 2002. 191 p. [in Russian].

\section{Сведения об авторах}

\section{About the authors}

Большаков Александр Михайлович, д-р техн. наук, член-корреспондент РАН, главный научный сотрудник, Институт физико-технических проблем Севера им. В.П. Ларионова СО РАН - структурное подразделение ФИЦ «Якутский научный центр СО РАН», г. Якутск, Российская Федерация

Aleksandr M. Bolshakov, Doctor of Engineering Sciences, Corr. Member of the RAS, Chief Researcher, V.P. Larionov Institute of the Physical-Technical Problems of the North of the Siberian Branch of the RAS, Yakutsk, Russian Federation

Захарова Марина Ивановна, канд. техн. наук, ведущий научный сотрудник, Институт физико-технических проблем Севера им. В.П. Ларионова СО РАН - структурное подразделение ФИЦ «Якутский научный центр СО РАН», г. Якутск. Российская Федерация

Marina I. Zakharova, Candidate of Engineering Sciences, Leading Researcher, V.P. Larionov Institute of the Physical-Technical Problems of the North of the Siberian Branch of the RAS, Yakutsk, Russian Federation e-mail: marine3@yandex.ru 